\title{
A New Adaptive Neuro-Fuzzy Inference System (ANFIS) Controller to Control the Power System equipped by Wind Turbine
}

\author{
Issam Griche ${ }^{1,3^{*}}$, Sabir Messalti ${ }^{2,3}$, Kamel Saoudi ${ }^{1}$ and M. Yaakoub Touafek ${ }^{1}$ \\ ${ }^{1}$ Department of Electrical Engineering, Faculty of Engineering, Bouira University, Bouira, Algeria. \\ ${ }^{2}$ Department of Electrical Engineering, Faculty of technology, M'sila University, Algeria \\ ${ }^{3}$ Mechatronics Laboratory (LMETR) - E1764200 Optics and Precision Mechanics Institute Ferhat \\ Abbas University Setif 1 Algeria.
}

\begin{abstract}
This study proposes a new Adaptive Neuro-Fuzzy Inference System (ANFIS) controller to control the power system tuned by a wind turbine. The purpose of design is to improve the dynamical response of power systems after fault which the voltage controller has been improved. The effectiveness of the proposed approach is studied under different situations of three machines 9 bus power systems which the wind turbine is replaced by wind turbine equipped by ANFIS controller. The simulation results confirm that the tuning method is able to preserve optimal performances over wide range of disturbances. The results have demonstrated the high performances of the proposed technique in terms of low oscillation, ripple, rapidity and accuracy.
\end{abstract}

\section{Introduction}

Electrical energy is a flexible, adaptable form of energy, but it is difficult to store, and consumption by customers and coincidental demand are constantly varying. These requirements necessitate permanent transmission and provision of energy via a distribution system by high voltage for high powers and long distances and low voltage for medium and low powers and short distances. The system is regulated by means of requirements placed on producers, in particular the requirement to keep the current frequency at $50 \mathrm{~Hz}$ (or $60 \mathrm{~Hz}$ ). Too much power results in an unwanted increase in frequency, while insufficient power causes a drop in frequency [1]-[2].

As the world shifts, its emphasis from fossil fuel to clean power, researchers are desperately searching for the perfect clean energy technology. Wind, solar, wave, tidal, biofuel and biomass are all experiencing renewed interest and new research funding. One alternative clean energy technology that bears looking at is wind powers which has been used for powering transportation and industrial equipment in cities and replace the power plants [3]-[4].

* corresponding author: griche_issam@yahoo.fr 
Among them, high Large-scale integration of wind power generation has been tested. Previous studies indicate that the increase of wind power penetration in such isolated power systems in a reliable way, it is important to have good wind-power [5] for the correct planning and operation of the power system [6]. The focus of recent research has been on a stability problem during integration in power system [7]. However, very few publications can be found are available in the literature that discusses to solve this problem of stability [7].

However, a compromise between stability and accuracy is necessary for the performance of ideal controller. To surmount this requirement, Adaptive Neuro-Fuzzy Inference System (ANFIS) offers several attractive properties for the tracking control, such as lack of sensitivity to parameter variations, external disturbance rejection and fast dynamic responses [8].

In this study, a new ANFIS controller is proposed to control voltage of power system in presence of wind turbine which strong three-phase fault is applied.

The rest of this paper is organized as follows: In section 2 provides the model of synchronous generator and the wind turbine. Section 3 the design of proposed controller. Section 4 represents the simulation results. Finally, section 5 concludes the paper giving some comments and future directions.

\section{Power system modelling}

Let consider an N-bus power system model with m-machines. The standard two-axis model of the generator with field winding on the direct axis and damper winding on the quadrature axis, an IEEE type-I excitation system and a simplified turbine/governor model are adopted in this study.

\subsection{Synchronous generator model}

In this study, the dynamic behavior of machines is described by the following equations. For $\mathrm{i}=1 \ldots \mathrm{m}$,

$$
\begin{gathered}
\dot{\delta}_{i}=\left(\omega_{i}-\omega_{b}\right) \\
\dot{\omega}_{i}=\frac{\omega_{b}}{2 H_{i}}\left[P_{m i}-P_{e i}-D_{i}\left(\omega_{i}-\omega_{b}\right)\right] \\
\dot{E}_{q i}^{\prime}=\frac{1}{T_{d 0 i}^{\prime}}\left[V_{e x i}-E_{q i}^{\prime}+\left(x_{d i}-x_{d i}^{\prime}\right) I_{d i}^{\prime}\right] \\
\dot{E}_{d i}^{\prime}=\frac{1}{T_{q 0 i}^{\prime}}\left[-E_{q i}^{\prime}-\left(x_{q i}-x_{q i}^{\prime}\right) I_{q i}^{\prime}\right]
\end{gathered}
$$

where $H_{i}, D_{i}, \omega_{i}, \delta_{i}, P_{m i}, P_{e i}$ are respectively the inertia constant, the damping constant, the rotor angular velocity, the rotor angle, the mechanical and electrical input power of the ith generator; $\omega_{b}$ is the rotating angular velocity. $T_{d 0 i}^{\prime}, T_{q 0 i}^{\prime}$ are the d-axis and q-axis transient time constants; $E_{d i}^{\prime}, E_{q i}^{\prime}$ are d-axis and q-axis transient emf; $x_{d i}^{\prime}, x_{q i}^{\prime}$ are generator $\mathrm{d}$-axis and q-axis transient reactances; $I_{d 0 i}^{\prime}, I_{q 0 i}^{\prime}$ are the d-axis and q-axis of the generator currents, $V_{e x}$ is the field voltage controlled by a voltage regulator. 


\subsection{Wind turbine model}

The mechanical power $P_{T}$ captured from a wind turbine of a blade radius (R) running in a wind stream of velocity $V_{w}$ is given by the equation:

$$
P_{T}=\frac{1}{2} \rho \pi R^{2} C_{p}(\lambda, \beta) V_{w}
$$

Where $\rho$ is the air density, $C_{p}$ is known as the power coefficient of the turbine. The tip speed ratio (TSR) is the ratio of turbine speed at the tip of a blade to the free stream wind speed and given by:

$$
\lambda=\frac{R \omega_{T}}{V_{w}}
$$

The power coefficient curve has been described in the literature by different fitted equations. In this paper, the power coefficient curve is approximated analytically by:

$$
C_{p}(\lambda, \beta)=0.5109\left(\frac{116}{X}-0.4 \beta-5\right) \exp \left(-\frac{21}{X}\right)+116 \lambda
$$

$$
\text { Where: } X=\frac{1}{\lambda+0.08 \beta}-\frac{0.035}{1+\beta^{3}}
$$

\section{Design of the proposed controller}

Adaptive Neuro-Fuzzy Inference System (ANFIS) is a combining between Neural Networks (NN) and Fuzzy Inference System (FIS), it can be applied to solve several optimization problems.

In this paper, the torque is optimized by the ANFIS controller shown in figure.1.

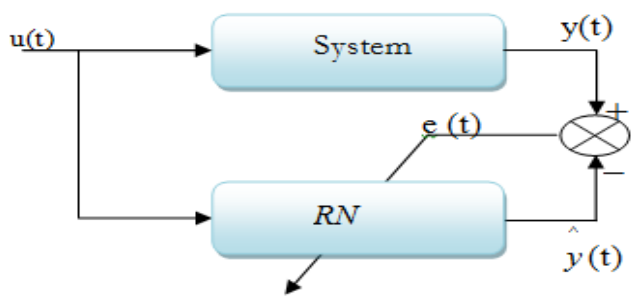

Fig 1. ANFIS controller proposed

The error equation $e_{i}=y-\hat{y}$ is used by an appropriate learning algorithm to adjust the parameters of the neural network. The Flow Chart of the proposed ANFIS controller is given by figure 2 .

The fuzzy controller in our case contains 25 rules used to link inputs to the outputs. The Artificial neural networks (ANN) are used to adapt the membership functions and the determination of fuzzy rules. The configuration is Adaptive Neuro-Fuzzy Inference Systems (ANFIS). The method used for the Neural-fuzzy system adaptation is called hybrid: a combination of optimization by the least squares method and refined by the back propagation of the error shown in figure 3. 


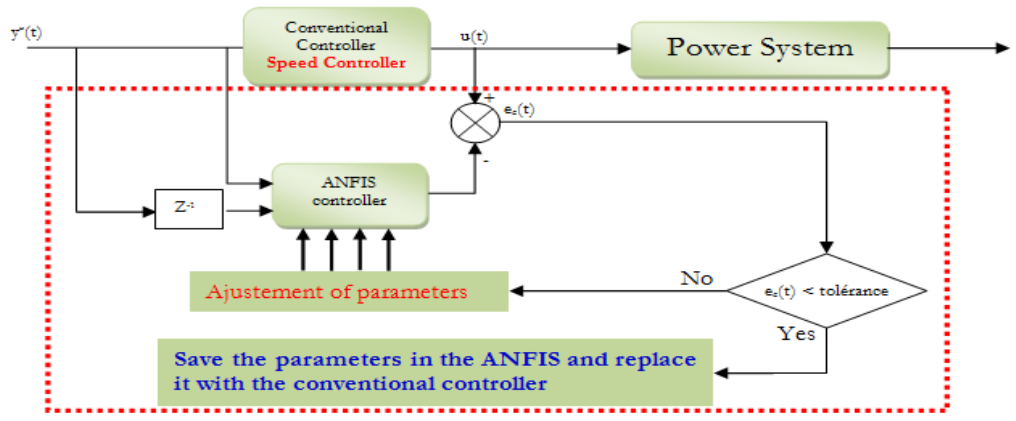

Fig 2. Flow Chart of the proposed ANFIS controller

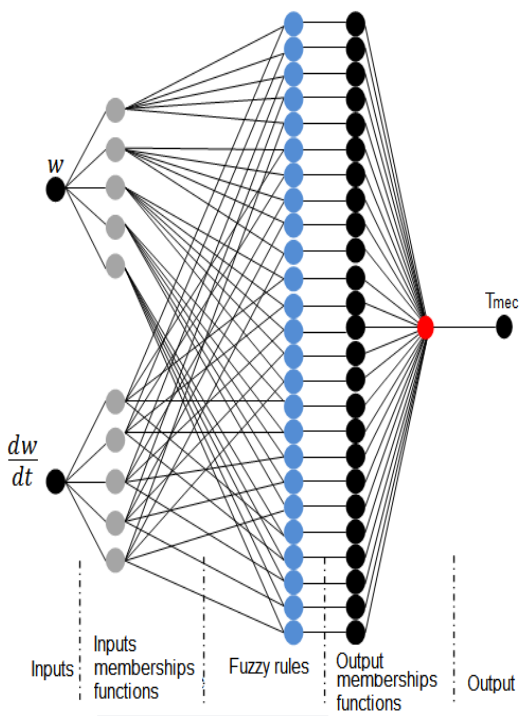

Fig 3. Proposed ANFIS controller

\section{Simulations and discussions}

In order to demonstrate the applicability, robustness and effectiveness of the proposed controller, simulation studies are carried out for the various fault disturbances and fault clearing sequences for three scenarios. The system being studied is simulated by MATLAB software. A 3 machines-9 bus IEEE system is used to evaluate the proposed model. Time domain simulations using Matlab-Simulink environment are performed for a strong threephase fault of $0.2 \mathrm{sec}$ applied to bus 4 at line 4-5.

\subsection{Scenario without integration of wind turbine}

In this scenario, the performance of the transient conditions is verified by applying a three phase fault at $\mathrm{t}=0.2 \mathrm{~s}$, on bus 4 at the end of line $4-5$ is considered.

The oscillations are shown in Fig. 4. As seen in this figure, the oscillations are quickly damped out which means better dynamical response and faster damping of oscillations.

It can be noted that the system is transiently stable in these conditions because the 
maximum value at which a fault is cleared after this disturbances.
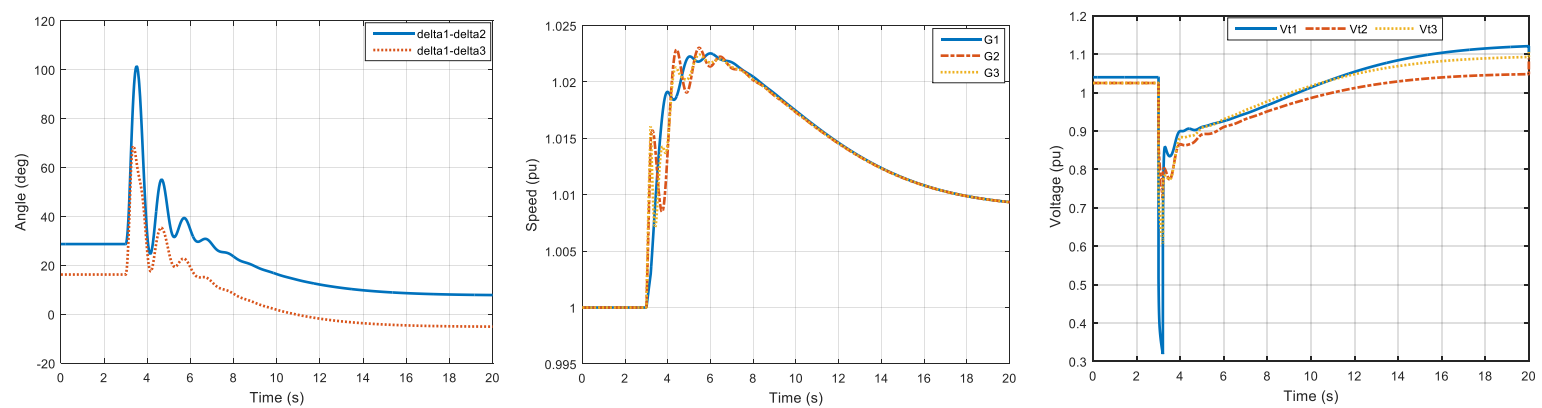

Fig.4. Simulation results without integration of wind turbine

\subsection{Scenario with integration of wind turbine}

In this scenario, another severe disturbance is considered for different loading conditions; that is, a three-phase fault is applied at the same above mentioned location in scenario 1.

For this simulation, it is assumed that a wind turbine occurred and replaced the generator 3. Fig. 5 displays the oscillations for the system response to this disturbance. It is obvious from this figure that the system loses its stability. As predicted, the criteria of stability in the presence of wind turbine have a longer value.
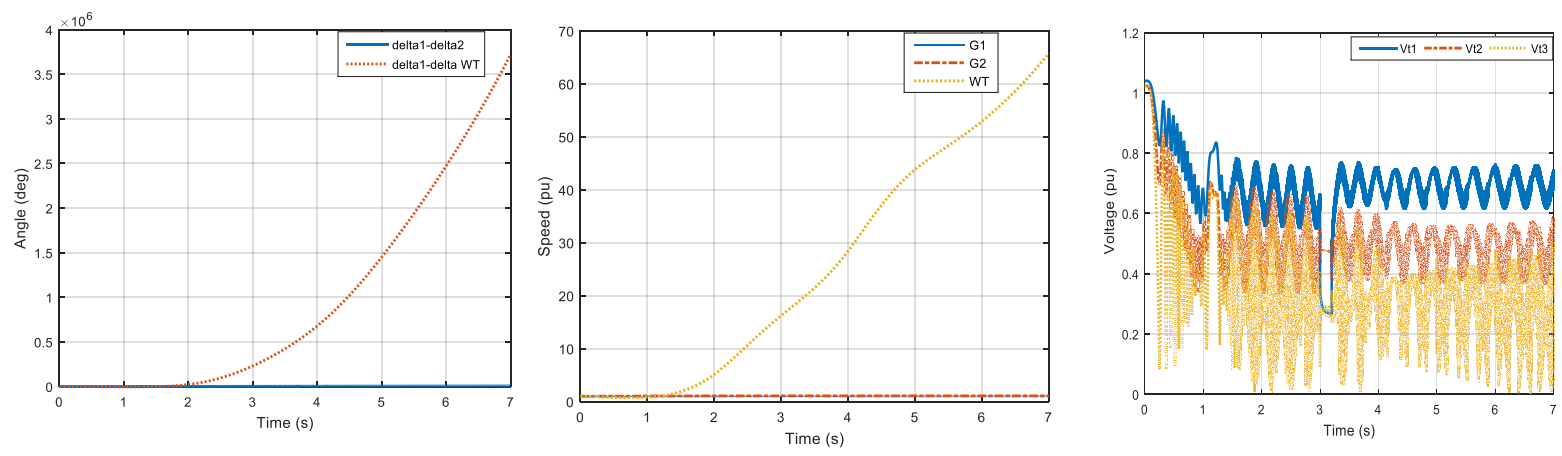

Fig.5. Simulation results with integration of wind turbine

\subsection{Scenario with integration of wind turbine equipped by ANFIS Controller}

Also, in this scenario, another severe disturbance is considered for different loading conditions; that is, a three-phase fault is applied at the same above mentioned location in scenario 1 and 2.

The fault is cleared with line tripping and the original system is restored upon the clearance of the fault. The system response to this disturbance is shown in Fig. 6.

Clearly, the ANFIS can suppress all oscillations satisfactorily. The best performance belongs to the proposed controller and has good damping oscillations and stabilizes the system quickly. 

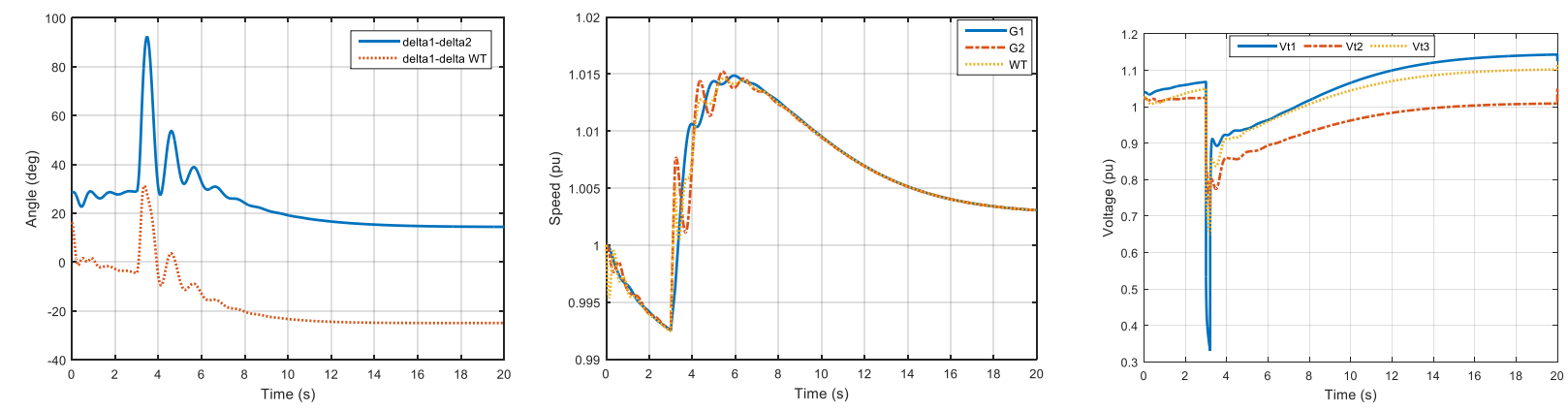

Fig.6. Simulation results with integration of wind turbine equipped by ANFIS controller

\section{Conclusions}

In this paper, a new ANFIS Controller is proposed to damp power system oscillations tuned by a wind turbine. To improve the dynamical response of power system, in the proposed approach, ANFIS controller is added to the control loop of wind turbine. These results demonstrate that the proposed controller confirms better disturbance rejection, keeps the control quality in the wider operating range, and damps the power system oscillations.

\section{References}

1. Speidel S, Braunl T (2016) Leaving the grid-The effect of combining home energy storage with renewable energy generation. Renew Sustainable Energy Rev, 60:12131224.

2. Hammons T.J (2008) Integrating renewable energy sources into European grids, Int.J. Electr. Power Energy Syst, 30: 462-475,

3. Bhaskar K and Singh SN (2012) AWNN-assisted wind power forecasting using feedforward neural network. Sustainable Energy, IEEE Transactions on, 3(2): 306-315.

4. Li H.Z, Guo S, Li C.J and Sun J.Q (2013) A hybrid annual power load forecasting model based on generalized regression neural network with fruit fly optimization algorithm. Knowledge-Based Systems, 37: 378-387.

5. I.GRICHE, S. MESSALTI, K. SAOUDI, M. Y. TOUAFEK (2019) “A New Adaptive Neuro-Fuzzy Inference System (ANFIS) and PI Controller to Voltage Regulation of Power System Equipped by Wind Turbine”, European Journal of Electrical Engineering (EJEE), Vol. 21, No. 2, pp 149-155.

6. I.GRICHE, S. MESSALTI, K. SAOUDI (2019) "Parallel Fuzzy Logic and PI Controller for Transient Stability and Voltage Regulation of Power System Including Wind Turbine”,PRZEGLĄD ELEKTROTECHNICZNY, ISSN 0033-2097, R. 95 NR 9

7. I.GRICHE, S. MESSALTI, K. SAOUDI (2021) "Instantaneous Power Control Strategy for Voltage Improvement in Power Network Equipped by Wind Generator", Publication in Journal Européen des Systèmes automatisés JESA, Vol. 54, No.1, February, 2021, pp. 147-154.

8. I.GRICHE, S. MESSALTI, K. SAOUDI, M. Y. TOUAFEK, F.ZITOUNI (2021) "A New Controller for Voltage and Stability Improvement of Multi Machine Power System Tuned by Wind Turbine", Publication in Mathematical Modelling of Engineering Problems MMEP, Vol. 8 , No.1, February, 2021, pp. 81-88. 